\title{
Planning the Retrofitting of Heating Appliances: The HARP Project ${ }^{+}$
}

\author{
Fabio Maria Aprà 1,*,‡, Raymond Sterling 1, Marco Calderoni ${ }^{2}$, Pedro Luis Espejo ${ }^{3}$, \\ Laura Pérez del Olmo ${ }^{3}$ and Riccardo Marchetti ${ }^{4}$ \\ 1 R2M Solution Spain, S.L., 28032 Madrid, Spain; raymond.sterling@r2msolution.com \\ 2 R2M Solution Srl, 27100 Pavia, Italy; marco.calderoni@r2msolution.com \\ 3 CREARA CONSULTORES SL, 28028 Madrid, Spain; pel@creara.com (P.L.E.); lpo@creara.com (L.P.d.O.) \\ 4 ACCADEMIA EUROPEA Di BOLZANO (EURAC), 39100 Bolzano, Italy; riccardo.marchetti@eurac.com \\ * Correspondence: fabio.apra@r2msolution.com; Tel.: +39-33-5755-8066 \\ + Presented at the Sustainable Places 2020, Online, 28-30 October 2020. \\ $\ddagger$ Correspondence web page: https://www.r2msolution.com/people/fabio-maria-apra/.
}

Published: 23 December 2020

\begin{abstract}
HARP, or heating appliances retrofit planning, aims at motivating individuals to plan the replacement of their often outdated and fossil-fuel operated heating appliances with more efficient alternatives. The project, which starts its first heating campaign in winter 2020, expects to reach this goal thanks to the creation of a labeling heating system classification through the development of a user-friendly application (HARPa) and the active participation of professionals in the sector.
\end{abstract}

Keywords: heating appliances; consumer behavior; retrofitting; renewable energy; labeling system

\section{Introduction}

According to the EU Strategy on Heating and Cooling (H\&C), the need to warm up and refrigerate building environments accounts for half of the EU energy consumption. The main problem is that this energy is being largely wasted due to the fact that $65 \%$ of the installed heater stock in Europe is old and inefficient (installed before 1992). This factor is even more worrying in the residential sector (i.e., European households), because up to $85 \%$ of the energy consumption refers to space heating and hot water supply. Because the residential heating system stock in the EU is based on old technologies, it accounts for a significant share of the average individual's carbon dioxide emissions and, at a comprehensive level, up to $30 \%$ of the EU's overall $\mathrm{CO}_{2}$ emissions [1].

According to recent data from the European Heating Industry (EHI), the EU space heating market represents roughly 126 million installed appliances, $60 \%$ of which are over 15 years old and likely to be performing at $C$ or lower energy class levels (if compared with the EU labeling for new appliances). These data demonstrate the low energy performance of most of the installed heating stock on the continent. Furthermore, the average replacement rate of EU boilers is low, currently only $4 \%$ per year, and it especially happens in emergency situations (e.g., when the system breaks). This low replacement rate could be explained by the lack of awareness about the potential economic, comfort and environmental benefits of an efficient heating appliance among homeowners and building managers. Another reason could be related to the complexity of the diffusion of renovation processes.

In this context, the efficiency of heating installations deserves specific attention, given that space heating represents both the largest share in energy consumption in buildings and the highest potential for efficiency gains. The transition towards more sustainable and decarbonized solutions requires the renovation of heating appliances as well [2]. 
To face these challenges, the EU, as well as European countries at a national level, are putting in place policies and tools focusing on greenhouse gas emissions reduction and energy efficiency improvement. The heating sector is a critical one in this sense, and it should endorse efforts in the climate change combat, namely through the development of tools that help the consumer to make better choices to support combating harmful emissions and climate change and promote energy efficiency.

\section{The HARP Project}

HARP stands for heating appliances retrofit planning. It is a project funded by the European Union through the Horizon 2020 framework, focusing on five EU member states: Portugal, Spain, France, Italy and Germany. It started in May 2019 and gathers a consortium of 18 partners, with long-standing expertise in relevant work areas, involving stakeholders from the heating industry sector, consumer organizations, energy consultants, universities and national energy agencies.

The HARP project has the ultimate goal to raise consumer awareness about new heating solutions, accelerating the replacement rate of this type of equipment and significantly reducing the energy consumption in existing buildings by exploiting the developed energy label.

Through a dedicated application, the HARP project will enable individuals to get an indication of the labeling classification of their heating system. The application will also provide an estimation of the costs associated with it related to, for instance, energy consumption or maintenance. Its name is HARPa and it will also give an overview of the most efficient alternatives available on the market, along with a list of their benefits, such as energy and costs savings, reduction of $\mathrm{CO}_{2}$ emissions, improvement of indoor air quality or noise reduction. Finally, HARPa will list the incentives and financial support available at national level to replace inefficient heating appliances with a more efficient alternative.

To get to understand the user environment framework, the HARP starting point was the definition of the Theory of Change Model, which analyzed consumers' behavior towards the adoption of new heating technologies. The model validated the results from previous studies and experiences which identified that the "indicative energy label for existing heating systems" can be a trigger for consumer action. In fact, the main output of HARPa is to provide the user with a specific energy label for their existing heating appliance. If the user obtains a low energy efficiency class, he/she would be more willing to change the current boiler. Additionally, the Theory of Change Model identified some key points to address consumers' concerns, such as the most relevant communication means to convey the energy-efficient heating message to the final users.

One of the analyzed studies [3] surveyed homeowners in Italy, Spain, Belgium, France, Germany and the UK, asking them how they would react if their current boiler would be labeled with a low energy efficiency class. Almost a fourth of the respondents (24\%) replied that they would replace their existing heating appliance as soon as possible or within two years at most. This study was also the starting point for the development of the HARP questionnaire, addressed to tenants and homeowners about the knowledge they have about their heating appliances. The results demonstrate a lack of consumer awareness of the inefficiency of their actual systems.

In this context, it is important to notice that from the analysis of previous studies and the replies to the HARP survey, the reliability and the quantification of tailored information is essential for the final user. This is especially true if the data are given to the consumer in an objective manner and from professionals in the sector, leading to an increase of trust in the heating market and possibly to an effective change in consumer behavior (e.g., thinking about replacing an old appliance before it breaks down). Moreover, one of the main efforts to engage consumers is the translation of technical information in an easy understandable way, which avoids linguistic diversity (which is the energy label's main goal) and shows the current situation with infographics and simple statistics.

In this regard, since professionals have been recognized as the preferred information channel for consumers regarding the replacement of their heating system [4], the HARP project will target their competence development via training activities. In Section 6, the important role of the professionals in this context is described. 
The complexity of a system replacement includes factors such as the consumer demand profile, the geographical region, the average income, the installed heating appliance, etc. The range of options for replacement is immense, depending on the type of system (for instance, hot water heating and/or space heating), the available garden and/or roof space, the available technologies on the market and the ease of the replacement (which also includes the retrofitting of existing appliances). Under these contextual realities, the two different versions of HARPa are: (i) designed for the final users, without any level of complexity, with easy to follow steps to insert the data and a direct and visual evaluation of their existing appliance; (ii) aimed at professionals (namely energy experts, installers, system designers, retailers), explicitly providing a training program on how to interact with the consumer, promoting efficient heating solutions in the consumer advisory process, using the HARP resources and the online app. Moreover, experience and best practices gathered from the roll-out of activities with professionals and consumers will be shared on the project website.

Through market associations and in-the-field organizations, professionals will be reached to bring engaging information about the heating market to the customers. Their role will be to support the consumers, providing them with the necessary tools to facilitate their decision-making process. Furthermore, this collaboration will enhance professionals' skills and presence in the market, strengthening their business and overcoming the behavioral adoption barriers.

\section{The Current Heating Appliances Stock in EU}

This section aims to present the installed stock of heating appliances in the EU, in order to give to the reader an overview of the current situation and help them understand the importance of the implementation of a project like HARP.

The heating appliances have been distinguished into "domestic hot water (DHW), space heating" and "water heating".

The number of dwellings in the EU is 250 million and is almost equally divided into single-family house (125 million) and multi-family house dwellings (123 million). Considering the overall dwelling stock, $64.9 \%$ has been constructed before 1980 and $22.7 \%$ prior to 1945 . Only $3.7 \%$ of the stock has been constructed after 2010 [5].

Out of 160 million heating appliances, which account for 4.66 TW of total installed capacity, $76 \%$ are fossil fuel boilers (Figure 1), of which 121 million are gas boilers (58\%), while oil and coal boilers represent 18.5 and 10.4 million units respectively. Electric heaters are in total 25 million units, while renewables are represented by heat pumps with 8.3 million units, biomass boilers ( 4.7 million) and solar thermal systems (1.2 million) [6].

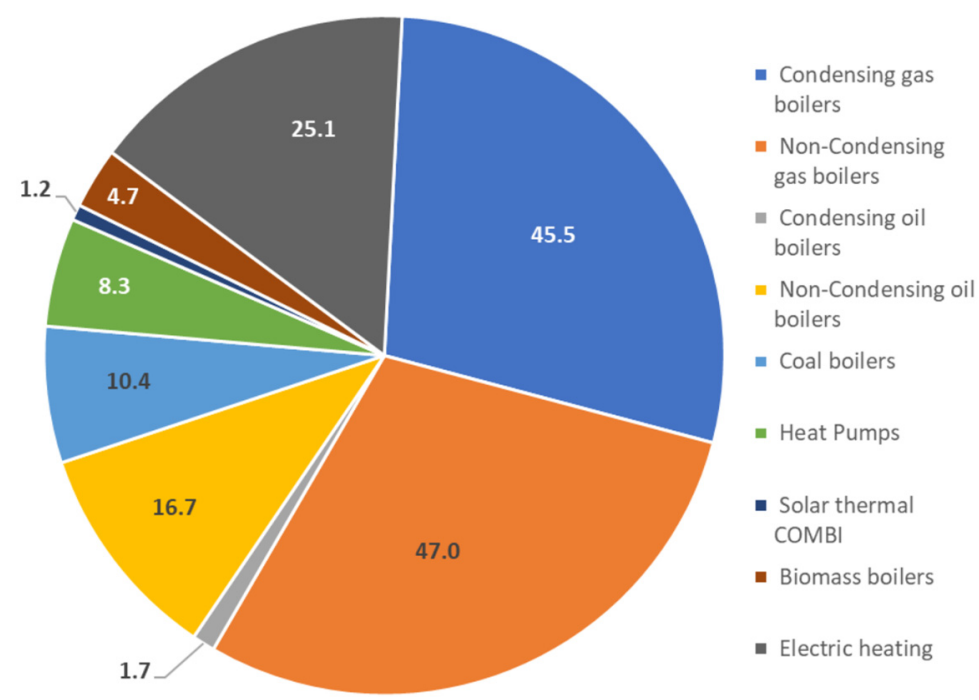

Figure 1. Space heating combined/space heating units installed in the EU in 2017 (in million units). 
All these different heating systems consume around 2574 TWh (including the heat pumps). Fifty-eight percent of the total consumption comes from fossil fuels boilers. Once again, the role of fossil fuel boilers is quite impressive: 1012 TWh from gas boilers, 304 TWh from oil boilers and 188 TWh from coal boilers. Biomass final energy consumption is $440 \mathrm{TWh}$, followed by district heating (257 TWh), heat pumps (256 TWh), electric heating (114 TWh) and solar thermal systems with just 3 TWh.

Regarding the water heating appliances in the EU, the research observed that the total amount currently is around 93 million units installed: 56.8 million are electric storage water heaters $(61 \%)$, 17.2 gas instantaneous water heaters (18.5\%), 8.3 million electric instantaneous water heaters $(8.9 \%)$, 6.4 million solar thermal domestic water heater systems (6.9\%), 3.6 million gas storage water heaters $(3.8 \%)$ and 400 thousand heat pumps (0.9\%) (Figure 2).

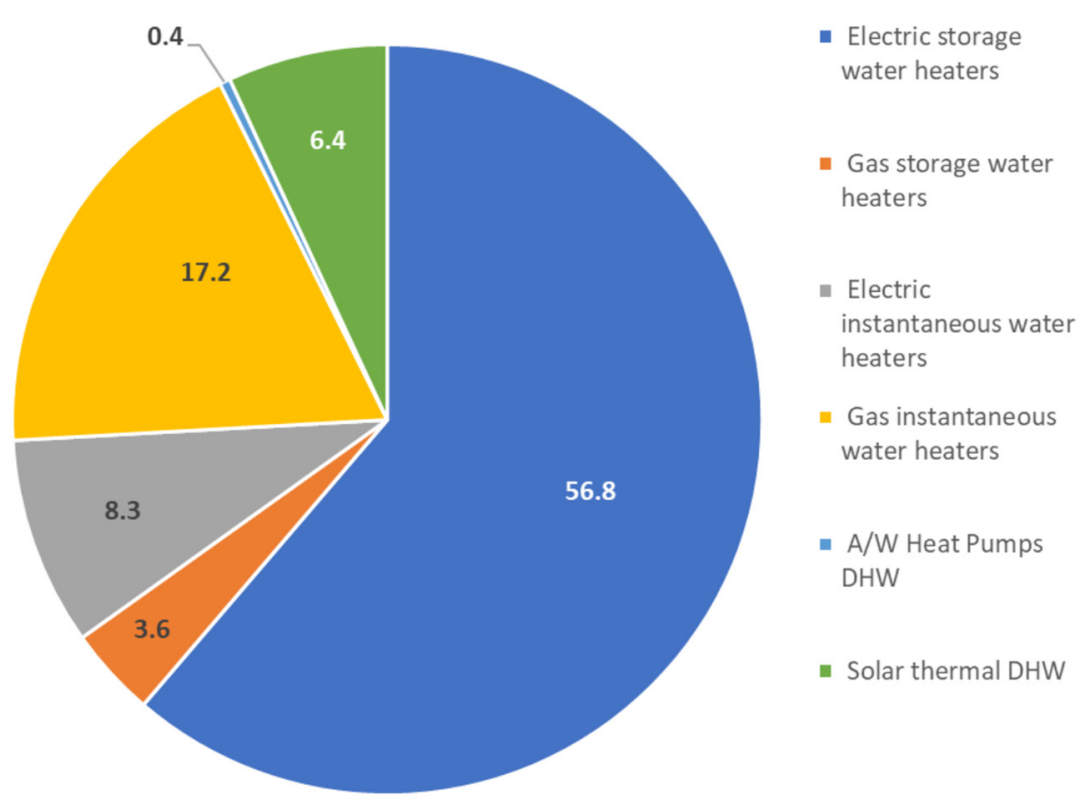

Figure 2. Water heating units installed in the EU in 2017 (in million units).

As explained in Section 1, 65\% of the installed heater stock in Europe is old and inefficient. In fact, the average European installation age for autonomous gas, oil and coal boilers is 28 years. These data reach a minimum in Italy for a gas boiler ( 3 years) and maximum in Portugal for oil boilers (22 years). In any case, there is a wide but clearly problematic range of ages. Heat pumps' installation age is available only for Portugal and it is between 9-10 years per unit. Portugal also provides data for solar thermal DHW systems (8 years), biomass boilers (13 years) and electric heating (23 years). Water heating average installation age is 15 years for all the countries analyzed, while for Portugal is 27 years.

\section{How to Encourage the Users in Replacing Their Heating System? The HARP Methodology}

With the aim of encouraging the renovation of old and inefficient boilers through the use of a specific energy labeling for existing appliances, HARP has developed its own engaging methodology, which can be classified in five different phases:

1. Awareness: this is the first stage of the process and it is a key one. There is a need to capture the attention of consumers and make them understand the opportunity of a change in heating and domestic hot water equipment before it gets broken and the choice has to be done in a rush. The fundamental channels to target the customer are direct contact through communication campaigns (online material, videos, seminars, social network posts) and indirect contact through professionals (who will be given specific training), and via public policy innovation. 
2. Quantification: the labeling of the current heating system gives the consumer a clear message of their installed appliance efficiency. It also allows the consumer to easily compare the efficiency of the existing boiler with the available options on the market and quantify the potential savings once the old heating system is replaced with a more efficient solution.

3. Market offer: showing consumers the available heating technologies on the market, both conventional and renewable, main characteristics, co-benefits and environmental improvements, finally indicating the energy class of the installed technologies.

4. Benefits: presenting consumers the potential for consumption savings, reduced maintenance costs, avoided $\mathrm{CO}_{2}$ emissions and other additional benefits (improved comfort, reduced noise, improved air quality, independence of energy prices, increased value of the house, etc.).

5. Motivation: the last step puts the consumer in contact with the professionals that can further support the acquisition process of the new heating system, making the consumer aware of the existing benefits, such as public financing and incentive schemes available at the country level, which can provide an extra reason for the replacement.

\section{HARPa, the Application for Users and Professionals}

To execute the previously presented methodology, the HARP consortium developed an online application, containing two different versions. The first version, aimed at individual consumers, will allow them to get information about their heating appliances easily and directly assessed from their homes, without major inconvenience and without having to spend extra time or resources to look for the information on the internet. The final output is the energy class of the existing heating appliance.

The second version is aimed at professionals. It is going to be more advanced, with more features and technical information, so that experts can explain in an easy way this type of data to consumers during maintenance visits or in the event of possible breakdowns. The application allows us to standardize the proposed methodology for any type of user, giving common, coherent and truthful information in the five countries where the project is carried out.

In both versions, once the required data have been inserted, the application will generate an energy efficiency label similar to the one already operative for new heating appliances. In addition, the application offers a new proposal for optimal and more efficient heating through the following indicators:

- Which technology among those currently available on the market is the optimal one for the consumer's specific heating needs, taking into account the house characteristics and the consumer's preferences in terms of economic/environmental benefits considered when replacing a heating appliance.

- The indicative power needed to use the new technology.

- The energy efficiency class achieved by the proposed technology.

- The indicative investment required to change the heating system.

- The estimated annual energy savings as a result of the change of system.

- The estimated annual economic savings due to the use of more efficient technology.

- Estimation of annual $\mathrm{CO}_{2}$ emissions savings from the change of heating system.

- Estimated energy, economic and $\mathrm{CO}_{2}$ emissions savings throughout the expected life time of the new heating appliance.

- Payback or term in which the initial investment is recovered by the savings obtained.

\section{The Essential Role of Experts in the Field and Professional}

As already depicted in the previous sections, professionals play a key role in accelerating the modernization of the EU's heating stock [4]. Considering their relevance in the consumer's decision process to replace heating appliances, they will be trained with the most relevant information on the heating market and on how to interact with the customer in a profitable way.

Information on one of the most important problems in the field, the comparison of prices between heating solutions, as well as information on the installed heating system, is not easily 
available for most consumers. Furthermore, it is difficult for them to compare technologies and solutions on the basis of lifetime costs and benefits, quality and reliability. The acquisition process of a new heating system relies mostly on professionals when a maintenance order is in place, or sales agents in the case of replacements and new acquisitions.

Consumer knowledge often comes from experts in the field and key professionals, more than from other sources such as the internet or friends. The installer's advice has often more impact on the customer's decision due to their professional knowledge. This kind of advice is especially important when it is urgent for the consumer to replace their heating system (e.g., when it breaks down and they do not have any time to do further research on their own). Additionally, consumers have been found to be more likely to switch to a more efficient heating system when they are aware of additional co-benefits, and are willing to spend extra money to achieve them [4]. These benefits go beyond cost savings: air quality, noise reduction, higher market value of the building, etc.

According to a recent study performed by the European Commission [5], installers usually advise on what they know and what they can do from their portfolio of knowledge, also depending on their available network. Furthermore, installers have a close connection with industry players, which can be a double-edged sword.

Under these circumstances, HARP aims to train professionals to help them to stand out from their competition since an improved interaction method with the consumer is put in place, promoting efficient heating solutions in the advisory process. By using a tool with a standardized methodology (HARPa), the investment forecast will not only remain stable, but users will also have more confidence in those professionals who use it. The HARP training can provide the professionals with additional and updated information about the available heating appliances on the market.

Additionally, in countries such as France and Germany, word of mouth is the most trusted communication channel for a professional to be contacted. This could result in a differentiating factor among the competitors. Those consumers who replaced their heating systems with more efficient ones thanks to the advice of a professional who uses the HARPa tool will see their energy bill reduced. As a consequence, these consumers will possibly share their positive experience with family, friends and co-workers among others, who will eventually contact the same professional to benefit from energy labeling and replacement of their heating system.

\section{Conclusions}

The low renovation rate of installed heating appliances has been recognized as an important issue to solve by the European Commission and strategic plans to improve the current situation have been developed. The high amount of fossil fuel-based technologies currently installed in the European countries have now became obsolete and too old to be kept in operation. On the heating market there are already more efficient solutions that can bring economic, environmental and extra benefits to the final user, but the lack of awareness regarding this theme is still a difficult challenge to overcome for the experts in the sector.

In this context, the HARP project aims at engaging and empowering the final user, giving them simple and secure information regarding the efficiency of their installed heating appliance and, if needed, providing available alternatives on the market, relating them to the user's needs. The development of a twofold application (HARPa), with a simpler version for users and a more detailed one for professionals, will give the interested parties in the field of heating appliances a tool to trust when retrofitting actions have to be taken.

Funding: These researches were funded by the European Union's Horizon 2020 CSA (Coordination and Support Action) under Grant Agreements: HARP \#847049.

Conflicts of Interest: The authors declare no conflict of interest. 


\section{References}

1. Ecofys. "EU Pathways to a Decarbonised Building Sector" How Replacing Inefficient Heating Systems Can Help Reach the EU Climate Ambitions. 2016. Available online: https://www.bdh-koeln.de/fileadmin/ user_upload/Studien/Ecofys_study_final_201604013.pdf (accessed on 10 October 2020).

2. European Commission. A Clean Planet for All a European Long-Term Strategic Vision for a Prosperous, Modern, Competitive and Climate Neutral Economy. 2018. Available online: https://ec.europa.eu/clima/sites/ clima/files/docs/pages/com_2018_733_analysis_in_support_en_0.pdf (accessed on 19 September 2020).

3. Wellkamp, D. Ein Beitrag zur Einschätzung der Konsequenzen der neuen Ökodesignanforderungen und Energieeffizienzkennzeichnungspflicht von Heizanlagen [Translated: A Contribution to the Evaluation of the Impacts of Ecodesign Requirements and Mandatory Labelling of Heating Installations]. Unpublished Ph.D. Dissertation, TU Dresden, Dresden, Germany, 2017.

4. Oliveira, T.; Neves, C.; Neves, J. Deliverable 2.1: Consumer Behaviour Change Model Regarding the Adoption of Efficient Heating Systems. 2020. Available online: https://heating-retrofit.eu/wp-content/uploads/ 2020/05/HARP-D2.1-Consumer-behaviour-change-model-EEHA-V1.1.pdf (accessed on 11 October 2020).

5. European Commission. Final Report on the Analysis of the Heating and Cooling Consumers and Recommendations in Terms of New Business Models and Regulatory Framework. 2019. Available online: https://www.rhc-platform.org/content/uploads/2019/12/Final-report-on-the-analysis-of-the-heating-and-c ooling-consumers.pdf (accessed on 11 October 2020).

6. Eurostat. Eurostat Regional Yearbook 2017. Available online: https://ec.europa.eu/eurostat/web/productsstatistical-books/-/KS-HA-17-001 (accessed on 10 October 2020).

Publisher's Note: MDPI stays neutral with regard to jurisdictional claims in published maps and institutional affiliations.

(C) 2020 by the authors. Licensee MDPI, Basel, Switzerland. This article is an open access article distributed under the terms and conditions of the Creative Commons Attribution (CC BY) license (http://creativecommons.org/licenses/by/4.0/). 